\title{
Cultivo in vitro de Brosimum gaudichaudii Tréc. (Moraceae)
}

LIMA, M.R. ${ }^{\prime}$; SANTOS, P.D.A. ${ }^{\text {; }}$ SILVEIRA, C.E.S. ${ }^{\text {; }}$ PALHARES, D. ${ }^{1,2}$; PEREIRA, L.A.R. ${ }^{1}$

1'Instituto de Ciências Biológicas, Universidade de Brasília-UnB, Departamento de Botânica, Campus Universitário Darcy Ribeiro. CEP 70910-900 Brasília, DF, Brasil. 2Autor correspondente. dariompm@unb.br

\begin{abstract}
RESUMO: O objetivo desta pesquisa foi avaliar o potencial organogenético de entrenós, discos foliares, e raízes de Brosimum gaudichaudii utilizando 12 diferentes combinações dos fitorreguladores 6-benzilaminopurina e ácido naftaleno acético, em meio MS (diluído à metade), sólido (6,5 g de ágar), e com 20 g.L-1 de sacarose. Independentemente das combinações hormonais testadas verificou-se a formação de calos friáveis (2 a $20 \mathrm{~mm}$ de diâmetro) em $90 \%$ dos entrenós usados como explantes. No entanto, os tratamentos testados não foram capazes induzir calos ou gemas em raízes e em discos foliares. O estudo anatômico revelou a formação de meristemóides nas regiões mais externa e mais interna dos calos. Os resultados obtidos poderão servir de base para novos testes de indução de calos na espécie.
\end{abstract}

Palavras-chaves: ANA, BAP, regeneração in vitro..

ABSTRACT: In vitro cultivation of Brosimum gaudichaudii Tréc. (Moraceae). The objective of this research was to evaluate the organogenic potential of internodes, leaf discs and roots of Brosimum gaudichaudii using 12 different combinations of the plant growth regulators 6-benzylaminopurine and naphthalene acetic acid in MS medium (half strength), solid medium (6.5 g agar) and sucrose medium (20 g.L-1). Regardless the hormonal combination tested, we observed the formation of friable calluses (2-20 mm wide) in $90 \%$ of the internode explants. However, the treatments were not able to induce callus or buds on roots and leaf discs. The anatomical analysis revealed meristemoid formation in the outer and inner regions of the calluses. The results may serve as the basis for further testing of callus induction in this species.

Keywords: ANA, BAP, in vitro regeneration.

\section{INTRODUÇÃO}

Brosimum gaudichaudii é uma espécie frutífera muito comum no Cerrado brasileiro, cujo sistema radicular subterrâneo, formado por xilopódio, raiz pivotante e raízes secundárias, acumula psoralenos, na casca, em concentrações de até $3 \%$ do seu peso seco (Palhares et al., 2007a, b). Os psoralenos são furanocumarinas utilizadas em procedimentos chamados PUVA-terapia, empregados contra psoríase, vitiligo e várias outras doenças de pele (Whitton et al., 2008).

Existe grande interesse comercial no cultivo da espécie, tanto pela produção de frutos comestíveis, que podem ser empregados na culinária regional (sorvetes, geléias, sobremesas) como para a extração dos princípios ativos acumulados nas raízes (Almeida et al., 1998). Há trabalhos na literatura versando sobre a anatomia de B. gaudichaudii (Palhares et al., 2007 a,b), germinação de sementes (Sales et al., 2002; Faria et al, 2011), propagação via estacas de raízes (Silva et al., 2011) e micropropagação (Fidelis et al., 2000).

Até o momento, os estudos realizados não conseguiram estabelecer um protocolo de propagação eficiente para essa espécie devido, entre outros aspectos, a curta longevidade das sementes e ao seu elevado grau de contaminação endógena, que dificulta a produção de explantes para as etapas seguintes do cultivo in vitro. $\mathrm{O}$ uso de explantes nodais na micropropagação da espécie também não apresentou resultado satisfatório quanto ao estabelecimento de uma metodologia. Entretanto, a propagação vegetativa de $B$. gaudichaudii por estacas de raízes foi obtida de forma satisfatória (Silva et al., 2011), o que de forma alguma diminui a importância de se usar técnicas de cultura de tecidos, visto que essas técnicas possuem uma grande variedade de propósitos biotecnológicos tais como, micropropagação e cultura de células para biorreatores.

Este trabalho teve como objetivo verificar 
o potencial calogênico e organogênico do entrenó, disco foliar e raiz de $B$. gaudichaudii, bem como estudar a anatomia dos calos obtidos.

\section{MATERIAL E MÉTODOS}

\section{Material vegetal}

Sementes de Brosimum gaudichaudii foram coletadas de indivíduos ocorrentes em áreas de Cerrado, no Distrito Federal. As sementes foram despolpadas, secadas à temperatura ambiente por dois dias e em seguida postas para germinar em vermiculita úmida, sob fotoperíodo de $12 \mathrm{~h}$, e intensidade luminosa de $41 \mu \mathrm{mol} . \mathrm{m}^{-2} . \mathrm{s}^{1}$.

\section{Desinfestação}

Em câmara de fluxo laminar, as sementes, entrenós e folhas foram imersas em álcool etílico a $70 \%$, por um minuto e foram testados diferentes tempos de imersão $(0,15,30$ e 45 min) em solução filtrada de hipoclorito de cálcio, com $65 \%$ de cloro ativo (6 g.L-1). Posteriormente, foram feitos três enxágues de 1 min em água destilada, deionizada e autoclavada. Foram considerados contaminados os explantes que apresentaram crescimento de colônias de fungos ou bactérias visíveis a olho nu, após 15 dias da aplicação do tratamento.

\section{Cultivo in vitro}

Segmentos de raiz e de entrenó, com $1 \mathrm{~cm}$ de comprimento, foram inoculados horizontalmente em placas de Petri, e fragmentos de folha de $1 \mathrm{~cm}^{2}$, preservada a nervura central, foram inoculados com a porção adaxial em contato com o meio de cultura. Os explantes foram cultivados em meio MS (Murashige \& Skoog, 1962), diluído à metade, acrescido de BAP e ANA, em 12 combinações de concentrações (Tabela 1), 6,5 g.L-1 de ágar e 20 g.L${ }^{1}$ de sacarose. $\mathrm{O} \mathrm{pH}$ do meio foi ajustado $5,7-5,8$, para, a seguir, ser autoclavado por $20 \mathrm{~min}, \mathrm{a} 121^{\circ} \mathrm{C}$, sob $1.2 \mathrm{~kg} . \mathrm{cm}^{-2}$. Os explantes foram transferidos para sala de cultivo, a temperatura de $25 \pm 2{ }^{\circ} \mathrm{C}$, fotoperíodo de $16 \mathrm{~h}$ e intensidade luminosa de $41 \mu \mathrm{mol} . \mathrm{m}^{-2} \cdot \mathrm{s}^{1}$. A cada 15 dias os explantes foram subcultivados para meio novo por um período de 120 dias. Cada tratamento foi representado por duas placas com seis explantes cada, totalizando 12 repetições por tratamento. Após 30 dias da inoculação foi calculada a porcentagem e medido o diâmetro dos calos produzidos em cada combinação testada.

\section{Análise anatômica}

Os calos do $3^{\circ}$ ou $4^{\circ}$ subcultivos foram fixados em solução de cacodilato de sódio $(0,01 \mathrm{M})$ contendo glutaraldeído (2,5\%) e paraformaldeído
$(4,0 \%)$ por $6 \mathrm{~h}$ a $4{ }^{\circ} \mathrm{C}$. Em seguida o material fixado foi desidratado em uma série etanólica crescente e embebidos em historesina de acordo com as instruções do fabricante (historesina Leica). Secções transversais $(7-10 \mu \mathrm{m})$ dos calos foram feitas utilizando um micrótomo rotatório Leica modelo RM 2145, distendidos e aderidos às lâminas microscópicas em placa histológica a $45^{\circ} \mathrm{C}$. Subsequentemente, as lâminas foram coradas em Azul de Toluidina. O registro fotográfico foi realizado em Fotomicroscópio Zeiss Axioscope com câmera digital acoplada.

\section{RESULTADOS}

Em geral, a germinação de $B$. gaudichaudii foi superior a $90 \%$. Assim, a quantidade de explantes não foi limitante para a realização dos experimentos e forneceu material vegetal com melhor fitossanidade do que se obteria de plantas do campo. Os diferentes tempos de imersão em hipoclorito de cálcio foram eficientes para a desinfestação da parte aérea: (a) por 15 min permitiu a obtenção de $75 \%$ dos entrenós e $93 \%$ dos discos foliares livres de contaminação; (b) por 30 min os valores foram de $93 \%$ e $100 \%$ para entrenós e discos foliares, respectivamente; e (c) por $45 \mathrm{~min}$ houve $100 \%$ de desinfestação desses dois tipos de explantes. No caso de raízes, nenhum desses tratamentos foi eficiente, resultando ou em 100\% de contaminação ou na morte de todos explantes.

A partir do quinto dia de cultura observouse a formação e o crescimento de calos friáveis na grande maioria dos entrenós em todos os tratamentos (Figura $1 \mathrm{~b}-\mathrm{f}$ ), cujo diâmetro variou de 2 a $20 \mathrm{~mm}$ de (Tabela 1); sendo que em discos foliares e raízes não se observou a formação de calos ou gemas (Figura 1a).

Nos primeiros subcultivos os calos ainda se encontravam friáveis, clorofilados e com sinais de presença de antocianina (Figura 1f-g); por volta do sétimo subcultivo, e após 100 dias de cultivo alguns calos se tornaram compactos. Nos poucos entrenós que não desenvolveram mostraram um considerável crescimento em diâmetro.

As análises anatômicas revelaram a presença de meristemóides, tanto nas regiões mais externa como na mais interna dos calos (Figura 2).

\section{DISCUSSÃO}

Não há relatos na literatura de protocolos estabelecidos para a micropropagação de $B$. gaudichaudii. A escolha dos fitorreguladores BAP e ANA para o experimento alicerçou-se no trabalho de Brum et al. (2002), para Ficus carica (Moraceae),

Rev. Bras. PI. Med., Campinas, v.16, n.2, supl. I, p.462-466, 2014. 
TABELA 1. Média dos diâmetros dos calos dos segmentos de entrenó nos tratamentos de ANA/BAP.

\begin{tabular}{ll} 
ANA+BAP $\left(\mathrm{mg}^{-\mathrm{L}^{-1}}\right)$ & Diâmetro $(\mathrm{mm})$ \\
\hline $0,5+0,5$ & $2,8 \pm 1,1^{*}$ \\
$0,5+2,5$ & $7,0 \pm 2,0$ \\
$0,5+5,0$ & $7,0 \pm 2,6$ \\
$0,5+10,0$ & $7,2 \pm 2,3$ \\
$2,5+0,5$ & $8,1 \pm 1,1$ \\
$2,5+2,5$ & $7,0 \pm 1,1$ \\
$2,5+5,0$ & $10,0 \pm 0,8$ \\
$2,5+10,0$ & $20,0 \pm 1,3$ \\
$5,0+0,5$ & $5,6 \pm 1,0$ \\
$5,0+2,5$ & $8,0 \pm 1,7$ \\
$5,0+5,0$ & $10,0 \pm 1,2$ \\
$5,0+10,0$ & $20,0 \pm 2,4$ \\
\hline
\end{tabular}

* média aritmética e respectivo desvio padrão. no de Dutta-Gupta et al. (1997) para Psophocarpus tetragonolobus e no de Flores et al. (2006) para Pfaffia tuberosa.

Nos casos em que a frequência de obtenção de plantas malformadas não for significativamente elevada, a indução de calos é uma fonte potencial de propagação como foi demonstrado com a planta ornamental Hoya Kerrii (Siddique, 2013). Além disso, a produção de calos pode ser fonte de produção de moléculas bioativas, de interesse farmacológico, dispensando o cultivo no campo (Bourgaud et al., 2001).

Por ser omeio MS utilizado nessa pesquisarico em nutrientes, isto contrasta com os solos do Cerrado que são pobres; assim, decidiu-se usar metade da concentração do meio MS original no intuito de se aproximar das condições de cultivo do ambiente natural da espécie. No entanto, a presença de nitrogênio tem sido relatada como fundamental para a embriogênese somática e para a diferenciação de partes aéreas (Ammirato, 1993). Diante disso, possivelmente a concentração reduzida de nitrogênio no meio de cultura pode ter
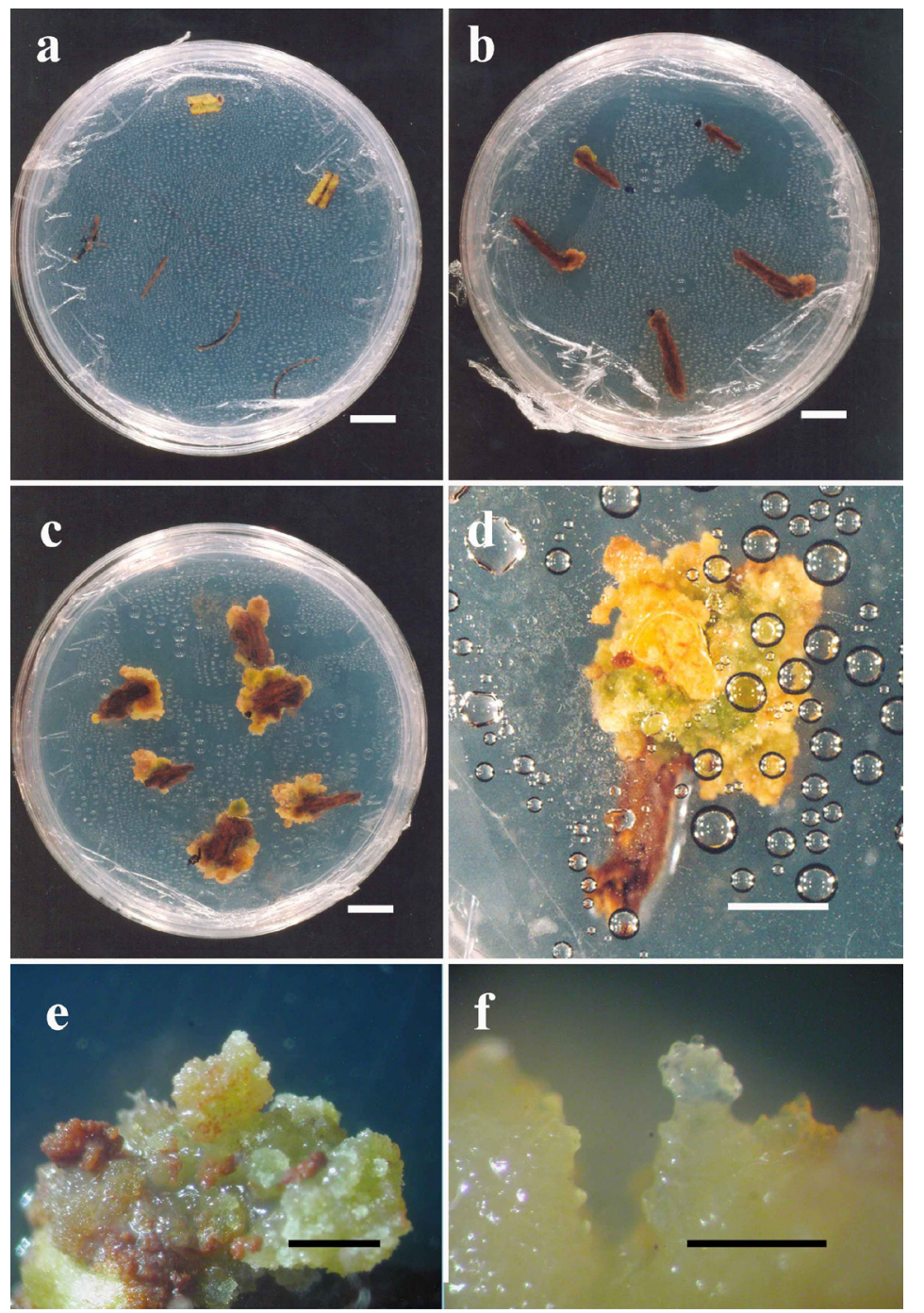

FIGURA 1. Calogenêse em Brosimum gaudichaudii. a, c-f) cultivado em BAP (10 mg. $\mathrm{L}^{-1}$ ) e ANA (2,5 mg. $\left.\mathrm{L}^{-1}\right)$. b) cultivado em ANA (0,05 mg.L-1). a) Discos foliares (vivos) e em raiz (tecidos mortos). Não ocorreu a formação de calos nesses tipos de explantes. b-f) Entrenó. b) Desenvolvimento de calos menores. c-d) Formação de calos maiores. e-f) Detalhe de porções do calo com coloração sugestiva de antocianina. Barra: $a-c=1 \mathrm{~cm} ; d=0,5 \mathrm{~cm} ; e-f=0,2 \mathrm{~cm}$. 


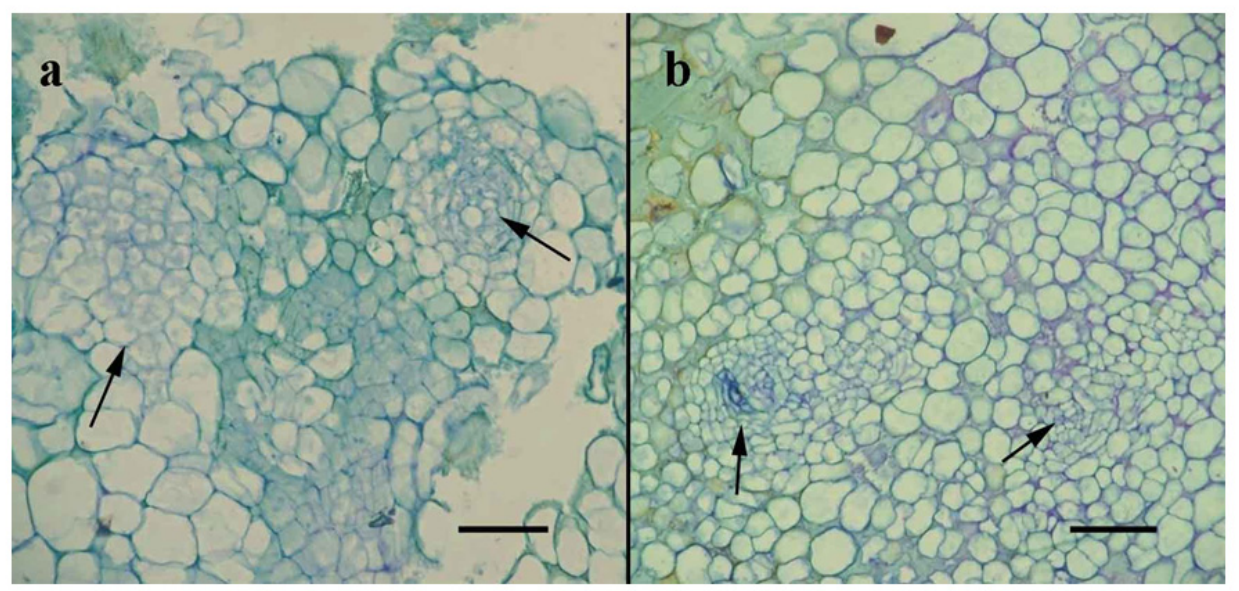

FIGURA 2. Aspecto dos Calos de entrenó em $1 / 2 \mathrm{MS}+10 \mathrm{mg} \cdot \mathrm{L}^{-1}$ de BAP e $5,0 \mathrm{mg} \cdot \mathrm{L}^{-1}$ de ANA, mostrando meristemóides (setas). a. região externa do calo; b. região interna do calo. Barra $=100 \mu \mathrm{m}$.

sido um fator limitante para a diferenciação dos calos (Holme et al., 1997).

As diferenças observadas na multiplicação e no desenvolvimento dos calos ocorrem devido à variação de resposta dos explantes à concentração dos fitorreguladores e às diferenças no teor endógeno de hormônios (Jimenez, 2005). Para a formação de calo, as concentrações mais elevadas de fitorreguladores foram as mais eficientes $\left(5,0-10,0 \mathrm{mg}^{\mathrm{L}-1}\right)$, visto que as concentrações mais baixas testadas não induziram respostas da planta estudada. Com base nos resultados, para se promover a indução de calos de entrenó de $B$. gaudichaudii as concentrações mais indicadas são: entre 2,5 e 5,0 mg.L-1 de ANA e 10,0 mg. L-1 de BAP.

Numa etapa subsequente, para estimular a formação de gemas ou embriões é recomendável o uso de concentrações mais baixas dos fitorreguladores como observado em açaí (Euterpe oleracea Mart.) onde a diferenciação e maturação dos embriões foram feitas sem adição de reguladores de crescimento (Scherwinski-Pereira et al., 2012). A utilização de TDZ (Thidiazuron), que tem sido eficiente, tanto na embriogênese quanto na organogênese de plantas lenhosas (Lu, 1993; Jones et al., 2007), e também pode representar uma alternativa para a propagação in vitro da mamacadela. Existe ainda um longo caminho a ser percorrido para se estabelecer o método eficiente de micropropagação de B. gaudichaudii; contudo, os resultados aqui descritos mostram que é possível alcançar esse objetivo. Além disso, a utilização dessa espécie é essencialmente extrativista e predatória, visto que o seu uso medicinal implica em destruição da planta inteira, pois as maiores concentrações de compostos medicinais estão no sistema subterrâneo da planta, e um método eficiente de micropropagação será de grande importância na sua conservação.

\section{AGRADECIMENTOS}

Ao técnico Elias Cavalcante pela assistência e a FINATEC e ao CNPq pelo apoio financeiro.

\section{REFERÊNCIA}

ALMEIDA, S.P.; PROENÇA, C.P.B.; SANO S.M.; RIBEIRO, J.F. Cerrado: Espécies vegetais úteis. Planaltina: Embrapa - CPAC, 1998, p.81-84.

AMMIRATO, P.G.V. Embryogenesis. In: EVANS, D.A.; SHARP, W.R.; AMMIRATO, P.G.V.; YAMADA, Y. Handbook of plant cell culture. New York: MacMilam PUBLISCHER COMPANY, V.1, 1993. 123p.

BOURGAUD, F.; GRAVOT, A.; MILESI, S.; GONTIER, E. Production of plant secondary metabolites: a historical perspective. Plant Sci., v. 161(5), p. 839-851, 2001.

BRUM, G.R.; SILVA, A. B.; PASQUAL, M. Efeito de diferentes concentrações de BAP e ANA na propagação in vitro da figueira (Ficus carica L.). Ciência e Agrotecnologia, Lavras. Edição Especial, p.14031409, 2002.

DUTTA-GUPTA, S.D.; AHMED, R.; DE, D.N. Direct somatic embryogenesis and plantlet regeneration from seedling leaves of winged bean, Psophocarpus tetragonolobus (L.) DC. Plant Cell Report, v.16, p.628-31, 1997.

FARIA, R. A. P. G.; COELHO, M. F. B.; MARTINEZ, M.; AZEVEDO, R. A. B. O uso de um modelo matemático no desenvolvimento de mudas de Brosimum gaudichaudii. Revista Verde, v. 6, n. 5, p.54-60, 2011.

FIDELIS, I.; CASTRO, E. M. C.; PINTO, J. E. B. P.; GAVILANES, M. L.; SANTIAGO, E. J. A. Características anatômicas de estruturas vegetativas de Brossimum gaudichaudii TRÉC. desenvolvidas in vitro e in vivo. Ciência e Agrotecnologia, Lavras, v. 24, n. 2, p. 327336, 2000.

FLORES, R.; NICOLOSO, F.T; VASCONCELLOS, N.J.S. Indução de calos e aspectos morfogenéticos de Pfaffia tuberosa (Spreng.) Hicken. Rev. Bras. Plantas Med., v.8, n.3, p.89-95. 2006. 
HOLME, I. B.; KROGSTRUP, P.; HANSEN, J. Embryogenic callus formation, growth and regeneration in callus and suspension cultures of Miscanthus x ogiformis Honda Giganteus' as affected by prolin. Plant Cell, Tiss. Org. Cult., v. 50, p. 203-210, 1997.

JIMENEZ, V. M. Involvement of plant hormones and plant growth regulators on in vitro somatic embryogenesis. Plant Growth Reg., v. 47, p. 91-110, 2005.

JONES, M.P.A.; YI, Z.; MURCH, P.K.S. Thidiazuroninduced regeneration of Echinacea purpurea $\mathrm{L}$. Micropropagation in solid and liquid culture systems. Plant Cell Reports, v. 26, p.13-19, 2007.

$\mathrm{LU}, \mathrm{C}$.Y. The use of Thidiazuron in tissue culture. In vitro Cell Develop. Biol., v.9, n.2, p.92-96, 1993.

MURASHIGE, T.; SKOOG, F. A. A revised medium for rapid growth and bioassay with tobacco tissue. Physiol. Plantarum, v.15, p. 473-497. 1962.

PALHARES, D.; de PAULA, J. E.; PEREIRA, L. A. R. ; SILVEIRA, C. E. S. Comparative anatomy of the bark of stems, roots and xylopodia of a Brazilian Cerrado medicinal plant, Brosimum gaudichaudii Tréc. (Moraceae). IAWA J., v. 28, n 3, p. 315-324, 2007a.

PALHARES, D.; DE PAULA, J. E.; PEREIRA, L. A. R.; SILVEIRA, C. E. S. Comparative wood anatomy of stem, root and xylopodium of Brosimum gaudichaudii (Moraceae). IAWA J., v 28, n 1, p. 83-94, 2007 b.

SALES, D.; ALBUQUERQUE, M.; COELHO, M; PIMENTA, S.; FAVALESSA, O. Germinação de sementes de Brosimum gaudichaudii Trécul submetidas a diferentes pré-tratamentos. Acta horticulturae, v. 569, p.137-140, 2002.

SCHERWINSKI-PEREIRA, J. E.; GUEDES, R. S.; SILVA R.; FERMINO JUNIOR, P. C. P.; LUIS, Z. G.; FREITAS, E. O. Somatic embryogenesis and plant regeneration in açai palm (Euterpe oleracea). Plant Cell Tiss Organ Cult ., v 109, p. 501-508, 2012.

SIDDIQUE, R. Micropropagation of Hoya Kerrii (Valentine Hoya) Through Callus Induction for Long Term Conservation and Dissemination. Int. J. Sci. Res., v. 2(8), p. 162-164, 2013.

SILVA, D.B.; VIEIRA, R.F.; CORDEIRO, M.C.T.; PEREIRA, E.B.C.; PEREIRA, A.V. Propagação vegetativa de Brosimum gaudichaudii por estacas de raízes. Rev.

Bras. Plantas Med., v. 13, n 2, p. 151-156, 2011.

WHITTON, M. E.; ASHCROFT, D. M.; GONZÁLEZ, U. Therapeutic interventions for vitiligo. J. Am. Acad. Dermatol., v. 59, p. 713-717, 2008. 